\title{
Samskara (processing) changes the quality of food: an analytical study
}

\begin{abstract}
Background: Ultimate impact of food depends not on its material qualities but largely on it's processing i.e. manner of cooking and the discipline of eating. The quality change in food is brought about by Karana (samskara) which can be understood as processing done to raw food item. The main purpose of samskara is to make food either difficult or easy for digestion and metabolism so that the required action is brought about in body by preventing the production or clearing of Ama at all levels. The radical scavenging activity can be considered as ability to prevent or clear ama at all levels.
\end{abstract}

Objectives: The objective of this work is to evaluate and compare the Amahara ability of Mudga Yusha prepared in three methods viz., open vessel, closed vessel and pressure cooking based on radical scavenging activity and $\mathrm{pH}$.

Materials and methods: Mudga (green gram) was procured from cultivator and the Yusha was prepared in three methods viz., open vessel, closed vessel and pressure cooking with grain water ratio 1:14. They were then analysed for palatability, $\mathrm{pH}$, and radical scavenging activity. The results were compared for its ability to reduce ama in body based on guruta and laghuta.

Results: The sensory analysis did not show any change in colour, aroma, taste and acceptability. The $\mathrm{pH}$ analysis revealed that the alkalinity of Yusha reduced in the order open vessel, closed vessel and pressure cooking. The radical scavenging activity was highest in open vessel and least in pressure cooking.

Discussion and conclusion: Ayurveda opines that the cooking of food in open vessel method makes the food lighter for digestion and metabolism thus increasing its ability to prevent formation of Ama or clear it. The results have proved this concept in dietary principle is true till date. By the analytical study proves that as guruta of food increases the Amaharatwa of it decreases. Hence foods that are guru should be consumed not on daily basis unless indicated.
Volume 7 Issue 4 - 2017

\author{
Kavita MB,' Sandeep S, ${ }^{2}$ Baskaran V, ${ }^{3}$ \\ Harshitha KJ' \\ 'Department of Swasthavritta and Yoga, Shri Dharmasthala \\ Manjunatheshwara College of Ayurveda and Hospital, India \\ ${ }^{2}$ Department of Swasthavritta and Yoga, Sushrutha Ayurvedic \\ Medical College and Hospital, India \\ ${ }^{3}$ Senior Principal Scientist, CFTRI, India
}

Correspondence: Kavita MB, Associate Professor, Department of Swasthavritta and Yoga, Shri Dharmasthala Manjunatheshwara College of Ayurveda and Hospital, Hassan, India, Email mbkhsn77@gmail.com

Received: January 0I, 1970 | Published: June 14, 2017

\section{Introduction}

"Aarogyam bhojanadhinam"means health depends on food one consumes . ${ }^{1}$ Throughout the history of medicine there has never been real separation between food and medicine. Hippocrates one of the most outstanding figures in the history of medicine and referred as father of modern medicine said "Let thy food be thy medicine and thy medicine be thy food". He was among the earliest to assert that diseases are caused by natural processes. He strongly believed that diseases are caused and treated by foods as body recognizes food particles as self and the medicines or extracts as foreign. This is what the basic dietary principles in Ayurveda highlights. It considers the planning of a biobalancing diet rather than a balanced diet. It puts great emphasis on the Trigunatmaka consideration of food, stressing especially a Sattwika diet, which is preferred for all. As per its dietary principles, any food which is properly metabolized will not cause any harm rather aids healing. ${ }^{2}$ Ultimate impact of food depends not on its material qualities but largely on its processing i.e. cooking and the discipline of eating. The foremost Ayurveda classic Charaka Samhitha describes eight principles related to food ${ }^{3}$ out of which the quality change is brought about by Karana (samskara) which can be understood as processing. It is said "Samskaro hi gunantaradhanamuchyate" meaning the quality transformation is brought about by the processing that we give to any substance or food stuff in its raw form. The main purpose of samskara is to make food either guru or laghu (difficult or easy for digestion and metabolism) so that the required action is brought about in body by preventing the production of Ama or clearing it at all levels. It is also done to bring the required quality change in raw food material before it is consumed. ${ }^{5}$

Concept of Ama is as old as concept of Agni, which is among the basic principles of Ayurveda. The concept of Agni is physiological while the concept of Ama is pathological. Always a process or a chain reaction starts and ends attaining certain form which is capable of carrying a function i.e., either synthesis (anabolic) or decay (catabolic). If this process of transformation gets hindrance due to any cause that state can be considered as Ama. It can be understood as "a state of substance resulting in the process of metabolism (paka) or transformation (gunantaradhana), but not attained paka or finality". ${ }^{6}$

The process of digestion takes place by action of Jataragni and the remaining part of metabolism takes place under influence of Bhutagni and/or Dhatvagni. The ama can also occur at this level of metabolism when bhutagni or dhatvagni are weak to perform their action to expected level. Radical is a group of atoms, entering and moving out of chemical combination, without undergoing change in configuration. ${ }^{7}$ Ama in circulation can be considered as 'radical'. When this particle reacts with molecular O2, it becomes peroxide radical or free radical which can be considered as 'Vidagdhakara paramanu' ${ }^{8}$ The free radicals are responsible for oxidative stress ending up in damage of proteins, lipids and vitamins affecting functioning of various important organs in body leading to diseases. ${ }^{9}$ This is usually a result of weak bhutagni (bhutagni mandyata), since the free radicals (vidagdhakara paramanu) do not change in their 
configuration there by not accepted by the target tissue (dhatu). The foods with action of pachana slowdown peroxidation damage and those prevent the formation of free radicals by enhancing the power of bhutagni or dhatvagni i.e., enhances release of secretion of various enzymes, hormones and chemicals for proper metabolism. Ayurveda handles the conditions caused by Ama through langhana, deepana, pachana and shodhana therapies where other medical systems struggle to do so.

This nutritive value analytical work was a post graduation dissertation work carried out under Rajiv Gandhi University of Health Sciences, Bengaluru at CFTRI, Mysore in the year 2013-14. A part of the work is used here. It aims at relating free radicals as ama and assesses the ability of the preparation to handle ama via the radical scavenging activity of an Ayurveda classical recipe prepared in three different methods. The two classical cooking methods mentioned in Ayurveda are either cooking with or without closure with a lid; current and common method in practice is using a pressure cooker. The free radical scavenging activity of recipe cooked in these three methods is compared to establish the relation.

\section{Objectives of the study}

Based on radical scavenging activity and $\mathrm{pH}$, to evaluate and compare the Amahara ability of Mudga Yusha prepared in three methods viz., open vessel, closed vessel and pressure cooking.

\section{Materials and methods}

Green gram was procured from a cultivator of Pillali village, Mysore taluk and Mysore District, Karnataka. All the chemicals and Standards were used of Analytical grade. Green gram was precleaned manually to remove stones and other foreign particles. Known quantity of Green gram was washed thoroughly to remove dirt and other adhering particles and soaked separately overnight (1216hours) to prepare Mudga yusha.

\section{Preparation mudga yusha ${ }^{10}$}

One part of soaked green gram was added to 14 parts of water ( $100 \mathrm{gms}$ of green gram was added to $1633 \mathrm{ml}$ of water). It was cooked up to semisolid consistency in three different methods viz., open vessel, closed vessel and in Pressure cooker. The Yusha prepared from all the three methods were subjected to radical scavenging activity.

\section{Sensory analysis}

Known quantities of samples were taken for Sensory evaluation conducted at the Department of Sensory Science, CFTRI Mysore.
Quantitative Descriptive Analysis (QDA) was used for analysis, which comprised of $15 \mathrm{~cm}$ scale anchoring at low $(1.25 \mathrm{~cm})$ or detection threshold and high $(13.75 \mathrm{~cm})$ or the saturation threshold. The intensity of each specific descriptor was quantified on the structured scale. Suitable attributes specific to Mudga Yusha were collected during the preliminary sessions of evaluations. Scorecards were prepared using the attributes which are typical of the Yusha. Panelists were suitably trained and oriented towards the sensory technique and the product to be evaluated. Care was taken to avoid interference from other sources or bias. Evaluations were conducted under white fluorescent light, with the booth area maintained at temperature $22 \pm 2{ }^{\circ} \mathrm{C}$ and RH $50 \pm 5 \%$. A suitable score card was developed using "Free-Choice Profiling" method selecting appropriate terminology. Samples were presented in $25 \mathrm{ml}$ beaker coded with 3-digit random numbers, to the panelists. A glass of water was also presented to cleanse the palate in between the samples. Mean scores were calculated and plotted against the attributes.

\section{$\mathrm{pH}$ - analysis}

Samples were allowed to attain $25 \pm 20 \mathrm{C}$ and its $\mathrm{pH}$ was measured using a suitable calibrated $\mathrm{pH}$ meter ( $\mathrm{pH}$-Analyser- cyber scan 2500). Samples were mixed (Centrifuge- BHG- Hermle-Z-360) vigorously (1000 rpm for 10minutes), taking $\mathrm{pH}$ of the supernatant after the solids have settled.

\section{Radical scavenging activity by DPPH method}

Radical scavenging activity of sample against stable DPPH (2, 2-diphenyl-2- picrylhydrazyl hydrate, Sigma-Aldrich Chemie, Steinheim, Germany) was determined spectrophotometrically. When DPPH reacts with an antioxidant compound, which can donate hydrogen, it is reduced. The changes in color (from deep-violet to light yellow) were measured at $517 \mathrm{~nm}$ on a UV/visible light spectrophotometer (Spectronic Genesys 8, Rochester, USA). Here radical scavenging activity of sample was measured by modified method of Duh and Yen. The reaction mixture contained sample, $1 \mathrm{ml}$ of methanol and $4 \mathrm{ml}$ of $0.5 \mathrm{mM}$ methonolic solution of 1, 1-diphenyl2-picrylhydrzyl (DPPH). The mixture was vortexed, allowed to stand at room temperature for 20 minutes. Absorbance of remaining DPPH was read at $517 \mathrm{~nm}$ against blank.

\section{Results}

\section{Sensory score card in Mudga Yusha}

The colour, taste and acceptability scoring of mudga yusha prepared from all three methods were similar except aroma (Tables $1 \& 2)$.

Table I Sensory score card in Mudga Yusha with the three cooking modes

\begin{tabular}{llll}
\hline Sample & Open vessel & Closed vessel & Pressure cooker \\
Color & Brownish yellow & Brownish yellow & Brownish yellow \\
Aroma & Pulsey & Pulsey & Green gram \\
& Bland & Bland & Sland \\
Taste & Saltish & Astringent & Astringent \\
& Astringent & Umami & Umami \\
Acceptability (15 scale scoring) & Umami & 9.9 to II & 9.9 to II \\
\hline
\end{tabular}

Table $2 \mathrm{pH}$ analysis of Mudga yusha with the three cooking modes

\begin{tabular}{lll}
\hline Mudga Yusha from Open vessel & Mudga Yusha from Closed vessel & Mudga Yusha from Pressure cooker \\
\hline $\mathrm{Ph} 8.58$ & 8.1 & 7.96 \\
\hline
\end{tabular}




\section{pH analysis of Mudga yusha:}

The $\mathrm{pH}$ of mudga yusha prepared from all three methods was alkaline. The alkalinity was least in mudga yusha from pressure cooker and highest was from that of open vessel.

\section{Radical scavenging activity of Mudga Yusha}

The radical scavenging activity of mudga yusha from open vessel method was 22.96, from closed vessel method was 20.1 and that from pressure cooking had the least of all 5.16 (Figure 1).

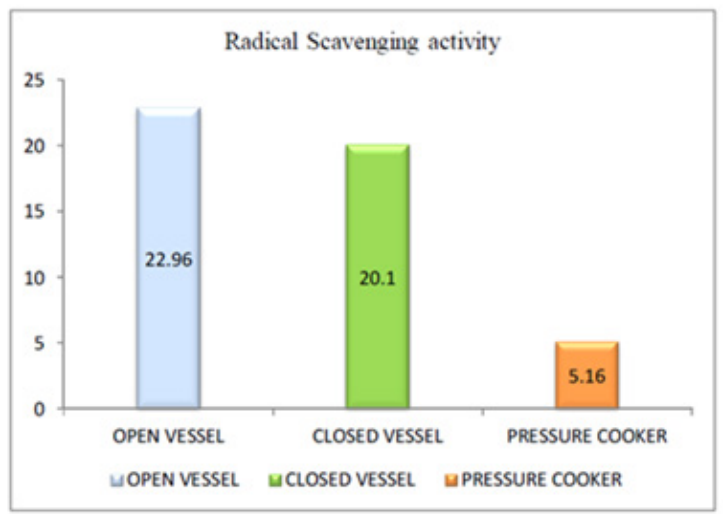

Figure I Radical scavenging activity value of Mudga Yusha with the three cooking modes.

\section{Discussion}

Mudga yusha prepared as per Ayurveda classics is said to be Kashaya Madhura ${ }^{11}$ (Astringent dominant sweetish) or madhura ${ }^{12}$ (sweetish) in flavor. The sensory analysis highlighted its Kashaya Rasa in Mudga yusha from all three methods. This hints that Yusha prepared in all three methods probably are alkaline. The $\mathrm{pH}$ analysis showed that all the three are alkaline and the alkalinity reduced from open vessel to that from pressure cooking.

The striking properties of Mudga Yusha are laghu (brings about lightness and easy to metabolize), ${ }^{13}$ deepana (increasing digestive and metabolic ability $)^{14}$ is its important action on body. The mudga yusha when cooked with open vessel was having higher alkalinity. As the alkalinity increases the actions like pachana and clarity ama increases. It is already known fact that as the alkalinity of food increases, the release of hydrochloric acid increases to keep $\mathrm{pH}$ of stomach acidic ${ }^{15}$ This indirectly shows the increase in ability to reduce ama in body by making digestion easier and smoother. This is further shown by the highest radical scavenging activity seen in Yusha prepared in open vessel method. The Yusha prepared from pressure cooking method had the comparatively lower alkalinity. Thus the action of pachana and clearing off the ama is reduced comparatively. The process also makes it guru for digestion as the process involves closed vessel added with pressure. This is further shown by the least radical scavenging activity seen in Yusha prepared in this method.

Ama can be briefly understood as a state of substance or food resulting during the process of paka (digestion or metabolism) or gunantardhana (/ transformation) but that which has not attained paka/ finality. Agni is the main cause for the transformation of food in body. After the action of jatharagni is over in gut, the transformation of food into the molecule similar to body tissue is majorly brought about by bhutagni. Unless this transformation takes place, the dhatvagni will be unable to convert food into body tissues. The laghuta (lightness) of food is important to enhance the power of agni. The foods cooked in open vessel are said to be laghu and those cooked by closing the vessel are guru. ${ }^{16}$ This makes it obvious that the ones cooked in pressure cooker become still heavier even with same ingredients of the recipe as the cooking takes place in a closed vessel under a high pressure. This also reduces the power to enhance agni (deepana) at the level of Buthagni or dhatwagni, if not the Jataragni.

Though it is said that the level of nutrition is maintained in pressure cooking method, the transformation of food into molecule similar to body tissues remains incomplete at the level of Bhutagni. Thus it will have less power to clear out Ama in body or it will at time produce ama at this level. This is evidenced by radical scavenging activity of the Mudga yusha prepared in these three different methods viz., open vessel, closed vessel and pressure cooking method. The radical scavenging activity of yusha prepared in open vessel method was as high as 22.96 while that cooked in closed vessel under pressure has as low as 5.16. All the ingredients of the Yusha were same in all the three methods. Here the methods adopted for cooking is Samskara which made the difference in quality of Yusha.

\section{Conclusion}

The foods prepared in open vessel method have higher ability to handle ama at the level of bhutagni when compared to the currently practiced pressure cooking method. The foods also will be easy to metabolize when cooked in open vessel and probably are hard to metabolize when cooked in pressure cooker as the guruta of food increases. Thus this proves Samskara (processing) brings about change in the guna (quality) of food thereby increasing or decreasing its specific action on body.

\section{Acknowledgments}

The authors acknowledge the support rendered by management and Head of Institution of Shri Dharmasthala Manjunatheshwara College of Ayurveda and Hospital, Hassan and Rajiv Gandhi University of Health Sciences, Bengaluru and Central Food Technology Research Institute, Mysore.

\section{Conflicts of interest}

Author declares there are no conflicts of interest.

\section{Funding}

None.

\section{References}

1. Soulié de Morant G. Précis de la Vraie Acuponcture Chinoise. Paris; Mercure de France; 1934.

2. Research Group of Acupuncture Anesthesia, Institute of Medicine and Pharmacology of Fujian Province. Studies of phenomenon of blocking activities of channels and collaterals. In: Zhang X, Editor. Research on Acupuncture Moxibustion and Acupuncture Anesthesia. Beijing, Science Press; Springer Verlag, Berlin, Germany. 1986, p. 653-666.

3. Travell JG, Simons DG. Myofascial Pain and Dysfunction: the Trigger Point Manual - the Lower Extremities. Williams and Wilkins, USA. 1992.

4. Mann F. Scientific Aspects of Acupuncture. London: William Heinemann; 1997. p. 63.

5. Melzack R, Stillwell DM, Fox EJ. Trigger points and acupuncture points for pain: correlations and implications. Pain. 1977;3(1):3-23.

6. Macdonald AJR. Acupuncture's non-segmental and segmental analgesic effects: the point of meridians. In: Filshie J, White A (Eds.), Medical Acupuncture: a Western Scientific Approach. UK: Churchill Livingstone; 1998. p. 83-104. 
7. Dorsher PT. Myofascial referred-pain data provide physiologic evidence of acupuncture meridians. J Pain. 2009;10(7):723-731.

8. Langevin HM, Yandow JA. Relationship of acupuncture points and meridians to connective tissue planes. Anat Rec. 2002;269(6):252-265.

9. Bai Y, Wang J, Wu JP, et al. Review of evidence suggesting that the fascia network could be the anatomical basis for acupoints and meridians in the human body. Evidence-Based Complementary and Alternative Medicine. 2011;2011:260510.

10. Tao H, Yu MC, Yang HY, et al. Correlations between fasciology and Yin Yang doctrine. J Acupunct. Meridian Stud. 2011;4(2):141-146.

11. Schorrenberger CC. Anatomical roots of Chinese medicine and acupuncture. J Chin Med. 2008;19(1,2):35-63.

12. Wong KC, Wu L-T. History of Chinese Medicine. Tiensin, China: The Tientsin Press; 1932.
13. Eycleshymer AC, Schoemaker DM. A Cross-section Anatomy. USA: Meredith Corporation; 1970.

14. Mann F. Textbook of Acupuncture. USA: Heinemann' 1987.

15. Macdonald A. Acupuncture from Ancient Art to Modern Medicine. Australia: George Allen and Unwin; 1982.

16. WHO. Standard Acupuncture Nomenclature. Geneva: World Health Organization technical report series; 1984.

17. Zhao ZQ. Neural mechanism underlying acupuncture analgesia. Prog Neurobiol. 2008;85(4):355-375.

18. The Academy of Traditional Chinese Medicine. An Outline of Chinese Medicine. China: Foreign Languages Press; 1975. 